\title{
DESIGN AND DEVELOPMENT OF A PERMANENT MOULD FOR CRUCIBLE PRODUCTION
}

\author{
M. O. Adeoti ${ }^{1,}{ }^{*}$, O. A. Dahunsi ${ }^{2}$, 0. O. Awopetu ${ }^{3}$ and O. I. Oyedeji ${ }^{4}$ \\ 1, Department of Mechanical Engineering, Federal Polytechnic, Bida, Niger State, Nigeria \\ 2, 4, DePt. of Mechanical Engineering, Federal University of TeChnology, AKure, Ondo State, NIGERIA

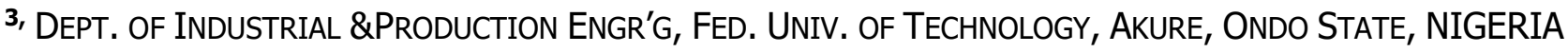 \\ E-mail addresses: 1 lymath2015@gmail.com, 2 tundedahunsi@gmail.com, \\ 3 olayinka.awopetu@gmail.com, 4 oluwaseyiisaac@yahoo.com
}

\begin{abstract}
This study aimed at development of a permanent mould for crucible production. Solid-Works was used as the computer aided design (CAD) tool for design and structural analysis of the parts, with necessary design considerations put in place. The fabrication of the mould was carried out at Federal Institute for Industrial Research Oshodi (FIRO), selecting Mild steel as the parent material. The mould basically consisted of the male and female parts made up of medium carbon steel because of the required strength. It was discovered from the structural analysis that the application of $1.0783 \mathrm{MN} / \mathrm{m}^{2}$ to produce the crucible from the mould is safe because it is not up to the vonmises maximum pressure of similar load of $5.584 \mathrm{MN} / \mathrm{m}^{2}$, this is lesser than the yield strength of the material which is given to be $2.481 \mathrm{MN} / \mathrm{mm}^{2}$. This shows that the material and its specification is safe and will not fail for the purpose for which it is designed for. Results showing the displacement and strain analysis revealed that the displacement in the mould is in the rate of $0.001 \mathrm{MN} / \mathrm{mm}$ and $0.00173 \mathrm{~mm}$. This displacement is insignificant to cause failure in the part. And the strain is seen to be in the range $2.176 \times 10^{-8}$ and $2.232 \times 10^{-5}$, the results therefore give confidence in the design to meet requirement.
\end{abstract}

Keywords: Casting, Development, Foundry, Crucible, Mould, SolidWorks

\section{INTRODUCTION}

The contributions of foundry technology to the overall technological and economic developments of a nation cannot be overemphasized. This is because virtually all industries directly or indirectly depend on cast products of variety of materials ranging from metals to non-metals whose production are results of foundry processes. This is evident in the articles produced in different industries such as automobile, machine tools, aerospace, electrical, plumbing, communication, food packaging $[1,2]$.

Foundry technology has been in existence and practiced both in the rural and urban areas for many decades now, yet the process has not developed to the level of aiding Nigerian technological advancement. These locally cast products do not meet the globally acceptable standard despite the availability of raw materials both in quantity and quality. This is responsible for much dependence on importation of goods and services [2, 3]. The growth of foundry industry in Nigeria can be said to be seriously affected by certain factors inhibiting it, some of which includes unstable electricity, lack of basic tools and implements, poor characterization of available raw materials, unskilled manpower, high level of illiteracy and high cost of importation of basic implement required for smooth running of the available furnaces $[3,4]$. These and many others are having ripple effects which has resulted into low productivity, high cost of production and even resulted to loss of jobs occasioned by closure of some of the industries [5]. The poor performance of manufacturing

\footnotetext{
* Corresponding author, tel: +234 - 703-871-1562
} 
sector in Nigeria is the testimony that is witnessed now, which has negatively impacted her economic development as well.

A crucible is a refractory container used in a furnace for metal, glass and pigment production as well as a number of modern laboratory processes, which can withstand temperatures high enough to melt or otherwise alter its content [6]. Crucibles are usually made from materials with high temperature resistance such as clay, graphite, silicon carbide and others. Crucibles help to keep metals when being heated in it in their good metallurgical conditions, help to keep heat and melt losses to a minimum and also help to avoid overheating of the metal thus minimizing oxidation or volatilization of charge constituents [6]. They are therefore often called metal melting pots. Other flasks or container used in foundry shops are moulding boxes and ladles [6].

Foundry crucibles are one of such basic implement that are literally scarce and relatively unavailable for small and medium foundry operators. These are ceramic vessels used where high temperature is required; they are stationary reaction vessels in which high temperature transformation takes place $[7,8]$. Shaping of ceramics has a long tradition, starting from free hand forming several thousand years ago up to the most sophisticated modern technologies like freeze casting, injection moulding, drying pressing, isostatic pressing and many more. The most important technologies for ceramic product manufacturing can be classified into casting technologies, plastic forming technologies and pressing technologies $[9,10,11]$.

A mould is an assembly of parts with a cavity or impression in it such that; when a placticized material is placed within it, it could be compacted easily to give an acceptable shape. When a mould is to be used repeatedly (high volume production) for a number of castings, usually having simple shapes it is called a permanent mould [12]

On the other hand, the mould is the cavity whose geometry determines the shape of cast part. Moulds can as well be classified as open and closed mould [13]. In open mould, the liquid metal is simply poured until it fills the cavity, while in a closed mould a passageway called gating system is provided to allow the liquid metal to flow from outside the mould into the cavity. As soon as the molten metal is in the mould, cooling and gradual solidification begins, but time is required for complete phase change. Once the casting has cooled sufficiently, it is removed from the mould. Mould can be made from a variety of materials metallic or non-metallic, such as cast iron, steel, bronze, graphite or ceramics, only that it should possess high refractoriness in nature [13]. However, most multipleuse moulds are made from metal for casting purposes. Casting literally can be defined as the process in which molten metal flows by gravity or other force into a mould where it solidifies to assume the shape of the mould cavity. The principles of casting simply involve melting the metal, pouring it into a mould, and allowing it to cool and solidify [10]. However, there are factors and variables that must be considered so as to accomplish successful casting operation. The first step in casting according to Adeoti [10], is pattern making. The pattern is made of suitable material, and is used for making cavity known as the mould. When this mould is filled with the molten metal and allowed to solidify, it forms the shapes of the pattern.

In crucible production, the mould unit as an assembly of parts, contained within it an impression into which plasticized material (clay) is placed, and then compacted at certain temperature and pressure to get a commercially acceptable shape. Moulds are generally available in two basic categories: expendable or temporary moulds and permanent moulds. Permanent moulds produce large numbers of dimensionally repeatable parts using moulds machined from cast iron or steel [14]. Expendable mould casting is a generic classification that includes sand, plastic, shell, plaster, and investment (lost-wax technique) moulds. All these methods use temporary, non-reusable moulds. After the molten metal in the mould cavity solidifies, the mould is broken to take out the solidified cast. Expendable moulds are suitable for very complex shaped parts and materials with high melting point temperature. However, the rate of production is often limited by the time to make mould rather than the casting itself [14]. Different crucibles with varying sizes are in already in use, these are mostly produced from expandable moulds, one major challenge encountered is the difficulty in ejection of the crucible after compaction with hydraulic press, this work however ease the ejection processes by designing a permanent mould with two halves fitly joined together with bolts and nuts.

This work looked to solve a lingering problem especially in Nigerian manufacturing Industry by designing and fabricating a permanent mould that can be used for the production of crucibles for low and medium enterprise. The aim of the research was to make a conceptual design of a permanent mould to be used in the crucible production using Solid Works as 
CADtools, considering the stress and structural analysis of force to be applied on the designed parts, and finally fabricate the two split mould following the design set up for crucible production.

\section{MATERIALS AND METHODS}

\subsection{Materials}

The major tool employed in this research work was the Solidwork used as CAD tools for design and structural analysis. The raw materials used were Mild steel because of strength and the service requirement which is the high resistance to shear and pressure. The work sequence adopted in methodology for the research work is highlighted in Figure 1.

\subsection{Materials for Permanent Mould Production}

Cast iron and steel are mostly used for making mould required for casting lower melting point alloys. According to Bhardwaj [14], mould materials for permanent castings must have the following properties:

i) Good Machinability. Since machining the cavity of mould is often the most significant cost factor.

ii) The mould must have good dimensional stability, high temperature strength, thermal shock and fatigue resistance.

iii) The mould material must have wear resistant to minimize dimensional changes caused during fettling of the cast products.

iv) Good thermal conductivity properties.

\subsection{Design Consideration in Mould Production}

Machining, draft and shrinkage allowances are considered in the design for effective performance of mould. Shrinkage allowance is the allowances provided to take care of contractions of a casting which occurs as the metal cools to room temperature. Shrinkage rule is used to compensate solid shrinkage depending on the material contraction rate [17]. The shrinkage rules for some materials are shown in appendix (Table 1).

The shrinkage allowance depends on the coefficient of thermal expansion (a) of the material. A simple relation which indicates that the higher the value of $a$, more is the shrinkage allowance. For a dimension ' $\mathrm{l}$ ',

$$
\text { Shrinkage allowance }=\alpha l\left(\theta_{f}-\theta_{0}\right) \text {. }
$$

Where $\theta_{f}$ is the freezing temperature and $\theta_{0}$ is the room temperature $[15 ; 17]$.

Draft allowance is the tapering of all the surfaces parallel to the direction in which the pattern will be removed slightly inward to facilitate safe removal of the pattern. Table 2 shown in the appendix 2 presented the draft allowances of some materials. The extra material, machining allowance that will be removed to obtain a finished product is included in the design of mould. The value of machining allowance depends on the size of the casting, material properties, material distortion, finishing accuracy and the machining method. Appendix 3 in Table 3 showed a machining allowance of various materials $[16 ; 17]$.

The mould is produced by machining its sections precisely from a metal block in two separate halves so that they fit together and may be opened and closed easily and accurately. The gating system as well as the part geometry is also machined into the mould. The piston core can be produce with or machined from a metal block and split in three parts for easy removal from the cast piston.

This work looked to solve a lingering problem especially in Nigerian manufacturing Industry by designing and fabricating a permanent mould that can be used for the production of crucibles for low and medium enterprise. The aim of the research was to make a conceptual design of a permanent mould to be used in the crucible production using Solid Works as CADtools, considering the stress and structural analysis of force to be applied on the designed parts, and finally fabricate the two split mould following the design set up for crucible production.

\subsection{Experimental Considerations and Mould Construction}

The major parts of the equipment designed and fabricated are female moulds and male mould.

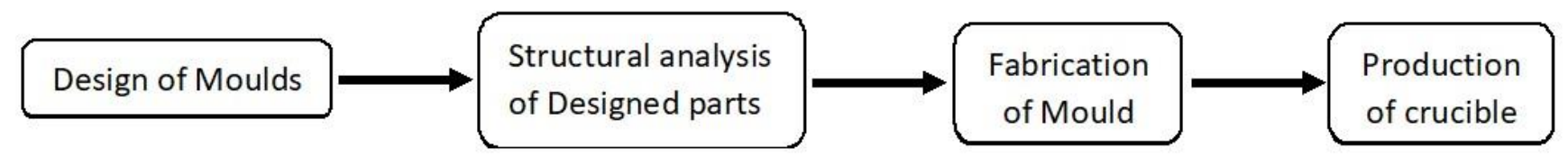

Figure 1: Work sequence 
The female moulds comprises of two (2) halves combining together and fastened with bolts and nuts to form a single component, and the male mould is a single piece joined to lower part of female moulds, forming the whole permanent mould. The computeraided design tool used for designing the moulds is Solid Works, and was also used for structural analysis of the moulds to ensure its structural integrity.

In the selection of the suitable materials for the mould production, several factors are considered which includes:

(1) Number of castings to be produced: A large scale production of crucibles was considered in design.

(2) Kind of moulding process: A gravity method of moulding was considered for use because a shorter cycle time was desired.

(3) Degree of dimensional accuracy and surface finish required: A fine and smooth surface finish was desired.

(4) Cost of Production: Minimum cost was desired.

(5) Life span: A long life span of the mould was desired.

Based on the above factors, metallic mould was selected, and medium carbon steel was selected as material for fabricating the moulds, and gravity method of moulding was adopted. The design considerations also put in place for making the moulds were that the thickness and section of the mould are made uniform as much as possible, sharp corners and edges are supported by suitable fillets to facilitate smooth flow of molten metal, easy withdrawal of mould and sound casting, a good surface finish is ensured in fabrication as it affect the finish of the casting and proper allowances were provided where necessary. Another consideration was that two piece or split pattern was selected to be used because of the shape and size of the crucible to be produced. The mould is in two halves to facilitate the removal of the casting from the mould. The outcomes of the computer-aided design of the female and male moulds from SolidWorks are shown in Fig. 2 and Figure 3.

\section{RESULTS AND DISCUSSION}

\subsection{Structural Analysis}

The press for applying pressure on the designed mould was applied at the top of the female mould, and was transmitted around the crucible slurry and the male mould. The maximum pressure for this press was estimated to be a $1.0783 \mathrm{MN} / \mathrm{m}^{2}$. The simulation of the responses of the mould to force applied that was obtained in terms of stress, displacement and strain are given in Figure 4

The result of stress analysis shows that the maximum Von Mises stress is $5.584 \mathrm{MN} / \mathrm{m}^{2}$, while the minimum Von Mises stress is $1.831 \mathrm{MN} / \mathrm{m}^{2}$ and it occurs around the lower area of the mould.

The result displayed in Figure 5 showed that the maximum Von Mises stress of $5.584 \mathrm{MN} / \mathrm{m}^{2}$ in the mould is lesser than the yield strength of the material which is given to be $24.816 \mathrm{MN} / \mathrm{m}^{2}$. This shows that the material and its specification is safe and will not fail for the purpose for which it is to be employed with the maximum pressure applied. Results showing the displacements and strain analysis revealed that the displacement in the mould is in the range of $0.001 \mathrm{~mm}$ and $0.00173 \mathrm{~mm}$. This displacement is insignificant to cause a failure in the part. And the strain is seen to be in the range $2.176 \times 10^{-8}$ and $2.232 \times 10^{-5}$. The results therefore give confidence in the design to meet requirements. For the male mould, the force is distributed around the part that the crucible will fill. In the male mould, the result of stress analysis shows that the maximum Von Mises stress is $5.006 \mathrm{MN} / \mathrm{m}^{2}$, while the minimum Von Mises stress is $0.708 \mathrm{MN} / \mathrm{m}^{2}$ and it occurs around the upper area of the mould.

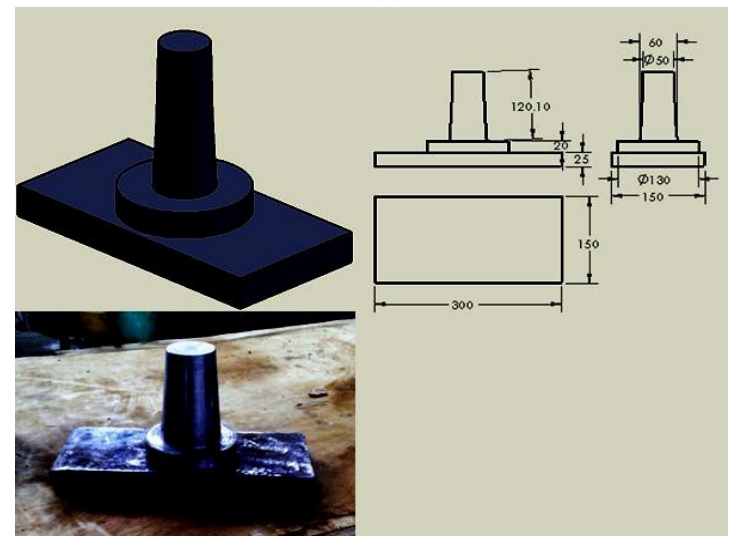

Figure 2: Male Mould

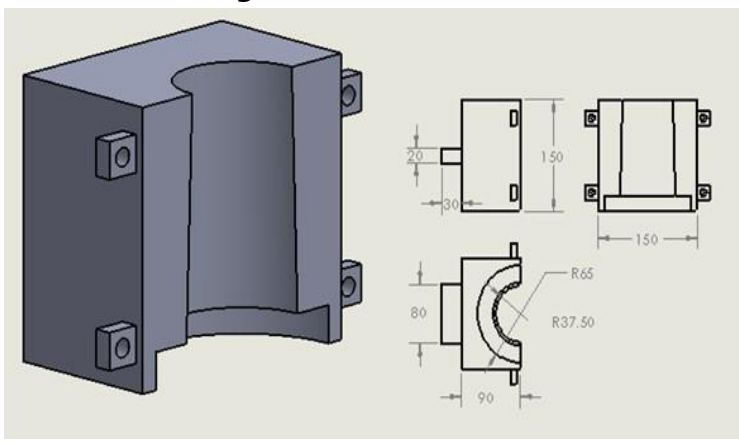

Figure 3: Female Mould 


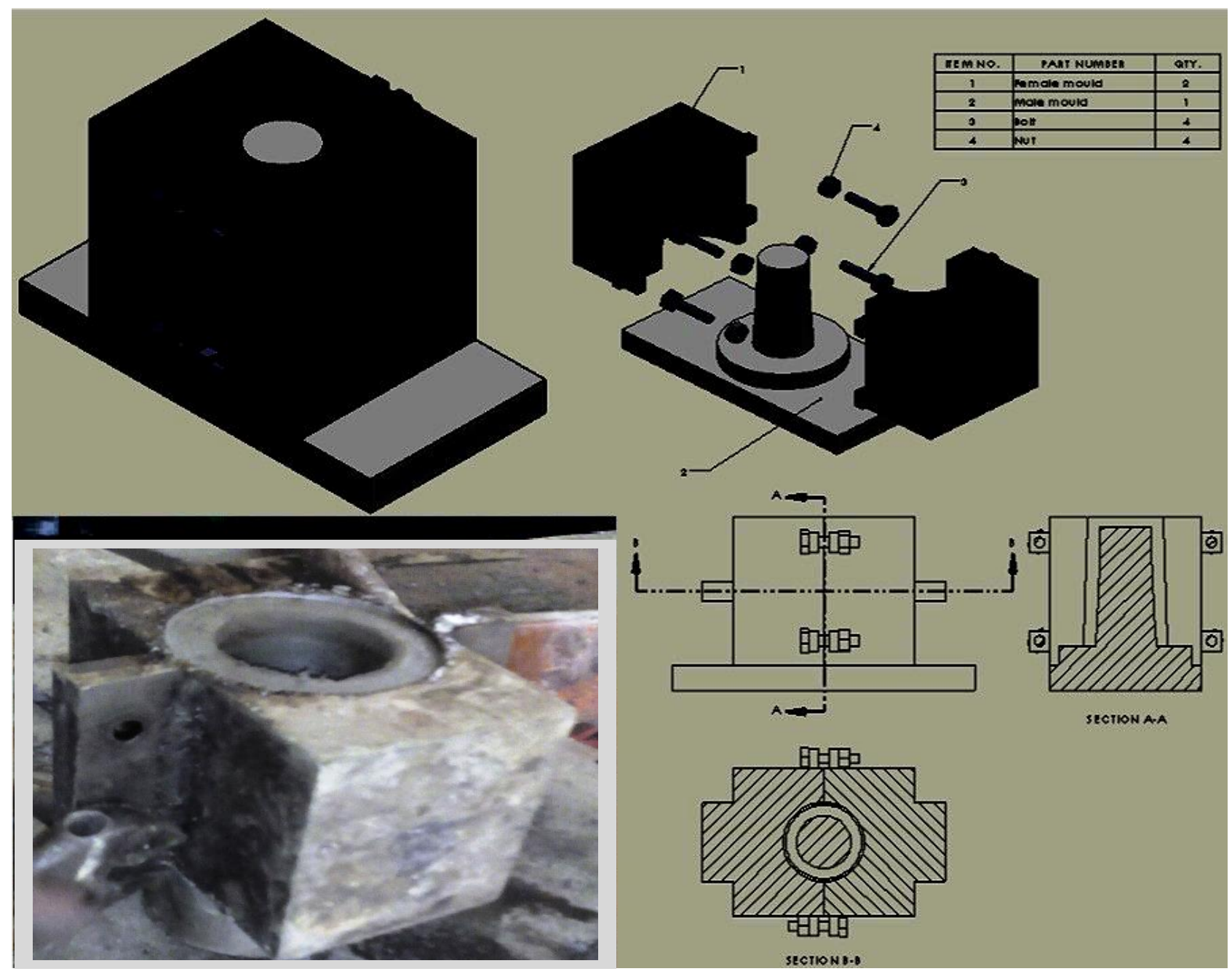

Figure 4. Assembly of Male and Female Mould

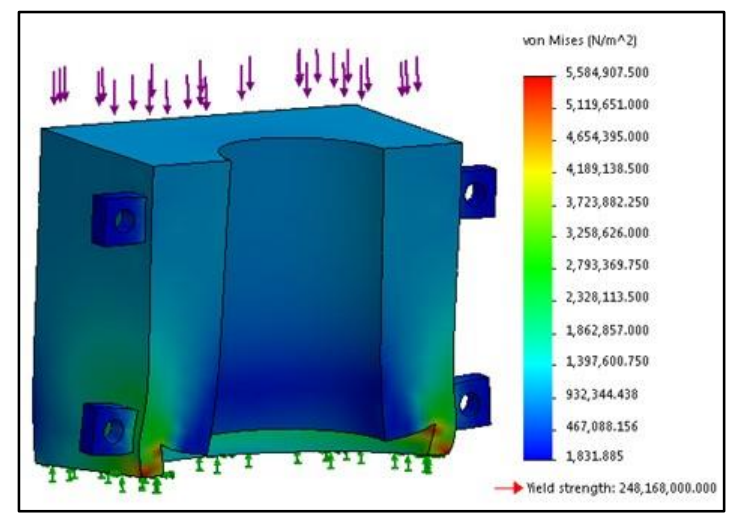

Figure 5. Stress Analysis on Female Mould

The result displayed in Figure 6 showed that the maximum Von Mises stress of $5.006 \mathrm{MN} / \mathrm{m}^{2}$ in the mould is also lesser than the yield strength of the material which is given to be $24.816 \mathrm{MN} / \mathrm{m}^{2}$. This enforces the idea that the material and its specification is safe and will not fail for the purpose for which it is to be employed. The maximum displacement that occurred in the male mould is shown to be

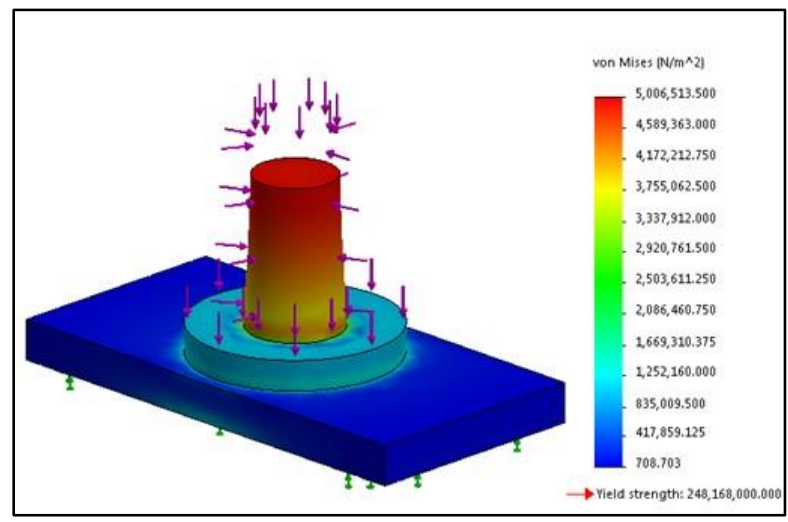

Figure 6. Stress Analysis on Male Mould

$0.003252 \mathrm{~mm}$ which is very small compared to the mould dimension. While the strain is in the range of $3.135 \times 10^{9}$ and $2.194 \times 10^{5}$. Therefore, the design is safe and should be able to meet the requirement for the mould. 


\subsection{Performance Evaluation}

The designed and fabricated mould was employed in the production of $2 \mathrm{~kg}$ life size clay bonded graphite crucible, the crucible was sun-dried, oven-dried and finally fired in the furnace to attain the required and specified temperature of $1200^{\circ} \mathrm{C}$. Thereafter, it was employed to melt Non-ferrous metals. The thermal cycle of the crucible was determined by the number of casting it can withstand before replacement. The product (crucible) obtained from the designed and fabricated mould is given in Plate 1.

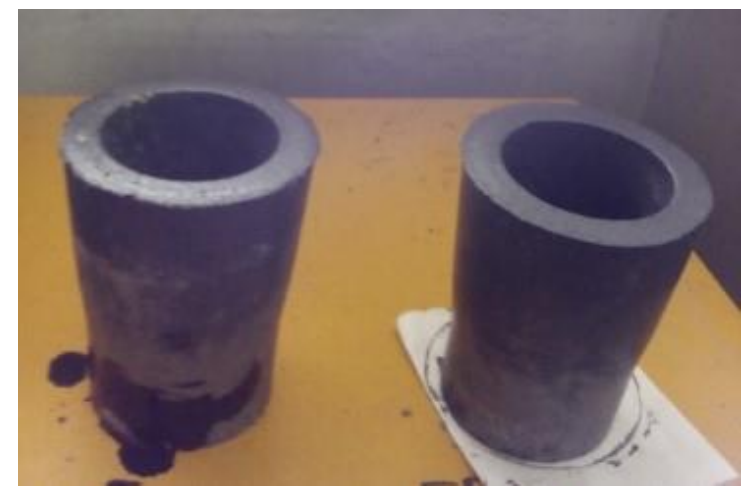

Plate 1: Produced Clay bonded Graphite Crucible

\section{CONCLUSION AND RECOMMENDATION}

The Designed mould considering the applied pressure and the corresponding structural analysis which shows that the applied pressure to produce the crucible was significantly lesser than the maximum shearing pressure, it can therefore be seen that the mould construction coupled with all the design parameters and inputs [18], the fabricated mould is therefore considered suitable for the production of $2 \mathrm{~kg}$ life size clay bonded graphite crucible. It is therefore recommended that the production of the mould should be made in commercial scale to make it accessible to foundry men, and thus will make the crucible widely available for use in casting. The fabricated mould is easy to operate, reduced labour requirements and minimal maintenance cost and it will enhance technological advancement and improves the economy of the nation.

\section{REFERENCES}

[1] Ahmed, A. S., Onaji, P. B. and Awareng, Z.A.: "Development of Graphite Crucible for the Iron and Steel Industry" Nigerian Journal of Engineering,Vol.10, No.1, pp 160-165, (2002).
[2] Ahmed, A.S.: "Development of graphite crucible for the industry", Journal of Nigerian Society of Chemical Engineer. Vol.9, No.2, pp 45-49, (2000).

[3] Asibeluo I. S.: "Fundamentals of Foundry Technology and Forging Operations". Second edition. Published by CEE EMMY VENTURES Agbor, Delta State,Nigeria, (2015)

[4] Asibeluo I.S. and Ogwor O .E.: Design of a 50Kilogram Capacity Cast Iron Crucible Furnace Using Locally Available Materials. International Journal of Research in Engineering and Technology, Vol. 4, No. 3. Pp 78-84; (2015)

[5] Degarmo, E.P., Black, J.T. and Ronald A.: Materials and Processes in Machining. $9^{\text {th }}$ Edition, Wiley press (2003).

[6] Aigbodion, V. S., Asuke. F., Neife S. I., Edokpia R.O. and Omah A.D: "Production of AluminoSilicate Clay-Bonded Bagasse Ash Composite Crucible by Slip Casting". Journal of Materials Environmental Science Vol.5, No.5, pp 1658-1666, (2014).

[7] Gupta A.: A Better Way to Cast Aluminium: Gravity Casting Aluminium in Permanent Molds Beats Conventional Sand and Pressure Die Casting. Materials Engineering; Penton Media Inc., p. 67, (2001).

[8] RMRDC: Multi-Disciplinary Committee Report of the "Techno-Economic Survey on Base Metal, Iron \& Steel and Engineering services sectors" (2003).

[9] Ogunrinola, G.O.: "Reassessing Nigeria's Technological Development Strategies" Engineering Conference Proceedings. Kaduna Polytechnic, Kaduna, Nigeria, (2000).

[10] Khurmi and Gupta J.K.: "A Textbook of Machine Design", 14 $14^{\text {th }}$ Edition. Eurasia Publishing House, (PVT) Ltd., Ram Nagar, New Delhi, (2005).

[11]

[12] Rajenda S.: Introduction to Basic Manufacturing Processes and Workshop Technology. New Age International (P) Ltd, Publishers, New Delhi, (2006).

[13] Fant M.:Permanent Mould Casting; Metal Casting Theory and Design. Available from http://en.wikipedia.org/wiki/Permanent_mold_ca sting; p. 2. [Retrieved on 2017-02-18], (2012).

[14] Adeoti, M. O., Binfa B. and Olaiya K. A.: Microstructural Analysis of Sand and GravityDie Cast Aluminum Scraps, International Journal of Applied Sciences and Engineering Research, Vol. 4 No. 1, pp. 57-67, (2015).

[15] Bhardwaj, A., Rawlani, M. V. and Mukherjee, C. K.: "Permanent Mold Casting"Excellent Casting 
Method for Manufacture of Automotive Components" International Journal on Recent and Innovation Trends in Computing and Communication Vol. 2 No. 8 pp.2254 - 2255, (2014).

[16] Groover M.P. Fundamentals of Modern Manufacturing: Materials, Processes and Systems. $4^{\text {th }}$ Edition, John Wiley and Sons Inc., USA. (2010).

\section{APPENDICES}

Table 1: Shrinkage Rule for Some Engineering Materials; Source: [17]

\begin{tabular}{|c|c|c|c|c|}
\hline Material & Dimension (feet) & Dimension $(\mathrm{mm})$ & $\begin{array}{l}\text { Shrinkage allowance } \\
\text { (inch/ft) }\end{array}$ & $\begin{array}{l}\text { Shrinkage } \\
\text { allowance (mm) }\end{array}$ \\
\hline \multirow{3}{*}{$\begin{array}{l}\text { Grey Cast } \\
\text { Iron }\end{array}$} & Up to 2 feet & Up to 609.6 & 0.125 & 0.529 \\
\hline & 2 feet to 4 feet & 609.6 to 1219.2 & 0.105 & 0.889 \\
\hline & Over 4 feet & Over 1219.2 & 0.083 & 0.703 \\
\hline \multirow{3}{*}{ Cast Iron } & Up to 2 feet & Up to 609.6 & 0.251 & 1.063 \\
\hline & 2 feet to 6 feet & 609.6 to 3657.6 & 0.191 & 2.426 \\
\hline & Over 6 feet & Over 3657.6 & 0.155 & 1.969 \\
\hline \multirow{3}{*}{ Aluminium } & Up to 4 feet & Up to 101.6 & 0.155 & 1.312 \\
\hline & 4 feet to 6 feet & 101.6 to 152.4 & 0.143 & 1.812 \\
\hline & Over 6 feet & Over 152.4 & 0.125 & 1.588 \\
\hline \multirow{2}{*}{ Magnesium } & Up to 4 feet & Up to 101.6 & 0.173 & 1.442 \\
\hline & Over 4 feet & Over 101.6 & 0.155 & 1.312 \\
\hline
\end{tabular}

Table 2: Typical Draft Allowances for External Surfaces, Internal Surfaces, Holes and Pockets ; Source: [17]

\begin{tabular}{lllll}
\hline $\begin{array}{l}\text { Pattern } \\
\text { Material }\end{array}$ & $\begin{array}{l}\text { Height of the given } \\
\text { surface (Inch) }\end{array}$ & $\begin{array}{l}\text { Height of the given } \\
\text { surface }(\mathrm{mm})\end{array}$ & $\begin{array}{l}\text { Draft angle } \\
\text { External (Surface) }\end{array}$ & $\begin{array}{l}\text { Draft angle Internal } \\
\text { (Surface) }\end{array}$ \\
\hline \multirow{4}{*}{ Wood } & 1 & 25.4 & 3.00 & 3.00 \\
& 1 to 2 & 25.4 to 50.6 & 1.50 & 2.50 \\
& 2 to 4 & 50.8 to 101.6 & 1.00 & 1.50 \\
& 4 to 8 & 101.6 to 203.2 & 0.75 & 1.00 \\
& 8 to 32 & 203.2 to 812.8 & 0.50 & 1.00 \\
\hline \multirow{4}{*}{ Metal and } & 1 & 25.4 & 1.50 & 3.00 \\
Plastic & 1 to 2 & 25.4 to 50.6 & 1.00 & 2.00 \\
& 4 to 8 & 50.8 to 101.6 & 0.750 & 1.00 \\
& 8 to 32 & 101.6 to 203.2 & 0.50 & 0.75 \\
\hline
\end{tabular}

Table 3: Machining Allowances of Some Engineering Materials Source: [17]

\begin{tabular}{lllll}
\hline Metal & Dimension (inch) & Dimension $(\mathrm{mm})$ & Allowance (inch) & Allowance $(\mathrm{mm})$ \\
\hline \multirow{3}{*}{ Cast iron } & Up to 12 & Up to 304.8 & 0.12 & 3.05 \\
& 12 to 20 & 304.8 to 504 & 0.20 & 5.08 \\
& 20 to 40 & 504 to 1,016 & 0.25 & 6.35 \\
\hline \multirow{3}{*}{ Cast Steel } & Up to 6 & Up to 152.4 & 0.12 & 3.05 \\
& 6 to 20 & 152.4 to 504 & 0.25 & 6.35 \\
& 20 to 40 & 504 to 1,016 & 0.30 & 7.62 \\
\hline \multirow{3}{*}{ Non ferrous } & Up to 8 & Up to 203.2 & 0.09 & 2.30 \\
& 8 to12 & 203.2 to 304.8 & 0.12 & 3.04 \\
& 12 to 40 & 304.8 to 1016 & 0.16 & 4.06 \\
\hline
\end{tabular}

